\title{
Derecho y tortura. Entre la defensa policial contra peligros y la persecución penal. Hacia la utilización en el proceso penal de una declaración obtenida bajo amenaza de tortura
}

\section{Law an Torture: Among Police Defence against Threats and Penal Procecution}

\author{
JÖRG EISELE *
}

Fecha de recepción: 26 de marzo de 2008

Fecha de aprobación: 21 de abril de 2008

\section{Resumen}

El Derecho contemporáneo establece importantes garantías a los ciudadanos, a fin de evitar la arbitrariedad por parte de las diferentes instancias del poder público. El presente artículo presenta un análisis que hace relación a la tención entre derecho y tortura; para ello se tomó como punto de análisis un caso real que se presentó en Alemania, en el cual un secuestrador declaró bajo la amenaza de la policía, este hecho llegó a los estrados judiciales y generó un intenso debate sobre los medios para obtener declaración y los derechos y libertades.

\section{Palabras clave}

Persecución penal, declaración, utilización de la tortura, derecho penal Alemán.

Profesor Universidad de Konstanz Alemania. El profesor Jörg Eisle, es docente de Derecho Penal en la Universidad de Konstanz, Alemania. El trabajo que recoge este número de la revista lusta, es el texto de la ponencia presentada por él, en el marco del seminario La Seguridad Pública en el Estado de Derecho del Siglo XXI, realizada por la Universidad Santo Tomás en mayo de 2006 y en desarrollo del convenio de cooperación académica existente entre esta universidad y la universidad alemana. 


\begin{abstract}
Contemporary law establishes important guarantees for citizens in order to prevent arbitrary behaviour by public authorities. The present article analyses the tension between torture and law with a real case from Germany, in which a kidnapper made a declaration with the threat of violence by police officers. This case produced an intensive debate on the civil rights and liberties as well as the methods applied by the police in the obtaining of information.
\end{abstract}

\title{
Key words
}

Penal prosecution, use of torture, German penal law.

\section{INTRODUCCIÓN}

El artículo se va a desarrollar en torno a cómo se puede delimitar la defensa policial contra peligros de la persecución penal y hasta qué punto puede ser utilizaba una declaración hecha bajo el miedo de la amenaza de tortura en un proceso penal posterior. En este punto también se debe mencionar la prohibición propuesta en el artículo 3 del Convenio Europeo para la Protección de los Derechos Humanos y de las Libertades Fundamentales.

\section{Caso inicial}

Tras el secuestro del hijo del banquero Jakob von Metzler la policía detuvo al presunto secuestrador, Magnus Gäfgen. Por orden del vicepresidente de la policía de Francfort los agentes de la policía amenazaron al secuestrador durante el interrogatorio causándole dolores, para así dar con el escondrijo del niño secuestrado y poder salvarlo. El autor del delito reconoció su participación bajo el miedo de la amenaza y reveló dónde estaba. No obstante, para aquél entonces el niño secuestrado ya había muerto.

Si bien es verdad que la Audiencia Provincial ( Landgericht) de Francfort declaró en el procedimiento penal por asesinato una violación de la prohibición de tortura por parte del funcionario encargado del interrogatorio, no quiso deducir ningún impedimento procesal (Audiencia Provincial, 2003, p. 323 y ss.). Por este motivo condenó al autor del delito a cadena perpetua.
Por su parte, la defensa mantuvo la opinión de que a causa de la amenaza de tortura, la declaración no debía poder ser utilizada y que, además, existía un impedimento procesal que obstaculizaba la condena. El Tribunal Federal Supremo (Bundesgerichtshof) rechazó el recurso de casación contra la sentencia por ser injustificada (21 de abril de 2004). El recurso de amparo constitucional no fue aceptado por decisión del Tribunal Constitucional Federal (Bundesverfassungsgericht), ya que la posibilidad de infracción de los Derechos Fundamentales no se explicaba de modo concluyente (2005, pp. 656 y s.). Por último, el autor del delito consiguió un éxito parcial, ya que su recurso por violación de la prohibición de tortura propuesta en el artículo 3 del Convenio Europeo para la Protección de los Derechos Humanos y de las Libertades Fundamentales, por lo menos, superó el procedimiento preliminar en el Tribunal Europeo de Derechos Humanos (2007, pp. 2461 y ss.).

\section{Fundamentos jurídicos}

En Alemania, la amenaza de tortura, así como la realización de la tortura atentan contra la dignidad humana, que está expuesta en el artículo 1, párrafo 1 de la Ley Fundamental alemana'; el presunto autor del delito es convertido en un mero objeto de la acción estatal, así, se menosprecia el estatus de persona, que también le debe ser

1 La dignidad humana es intangible. Respetarla y protegerla es obligación de todo poder público. 
reconocido al criminal ${ }^{2}$. Además, el artículo 104, párrafo 1, frase 2 de la Ley Fundamental alemana dice que las personas detenidas no pueden ser maltratadas ni psíquica ni físicamente ${ }^{3}$. Asimismo, la ya mencionada prohibición de la tortura contenida en el artículo 3 del Convenio Europeo para la Protección de los Derechos Humanos y de las Libertades Fundamentales es relevante 4 . Según la opinión predominante, aunque es verdad que esta prohibición adquiere sólo el valor de una simple ley, debe ser tomada en consideración a la hora de interpretar otras leyes como, por ejemplo, el código de procedimiento penal alemán (Tribunal Federal Supremo en Asuntos Penales, s.f., pp. 46, 93 y ss.; Beulke, 2006, número marginal 10).

Las reglamentaciones de los estados federados deben ser atendidas de modo especial en el ámbito de los interrogatorios policiales. Así, en el parágrafo 35, párrafo 1 de la Ley policial de Baden-Württemberg se dispone que la policía no puede utilizar la fuerza en interrogatorios para provocar una declaración. Para el ámbito de la persecución penal, el parágrafo 136a del código de procedimiento penal alemán contiene una reglamentación muy detallada sobre determinados métodos que están prohibidos en los interrogatorios ${ }^{5}$.

2 Leipziger Kommentar Rönnau (2007, § 32, número marginal 262). En el resultado igualmente se puede consultar Schönke, Schröder, Lenckner, Perron (2006, § 32 número marginal 62 a). En otro sentido, tras una diferenciación entre el núcleo de la dignidad y otros ámbitos de protección: Maunz, ,Dürig und Herdegen 2005, Art. 1 número marginal 45 y ss.)

3 "Las personas detenidas no podrán ser maltratadas ni psíquica ni físicamente".

4 "Nadie puede ser sometido a tortura o a una pena o trato inhumano o humillante".

5 "(1) La libertad del acusado de formar su voluntad y actuar así, no puede ser influida por maltrato, cansancio, intervenciones corporales, administración de remedios, tormento, engaño o hipnosis. La fuerza sólo puede aplicarse en la medida que el Derecho de procedimiento penal lo permita. Están prohibidas la amenaza con una medida no permitida por el Derecho de procedimiento penal, así como la promesa de una ventaja no prevista por la Ley.

"(2) No están permitidas las medidas que mermen la memoria o el discernimiento.

"(3) La prohibición de los párrafos 1 y 2 tiene validez sin consideración del consentimiento del acusado. Las declaraciones

\section{DEFENSA POLICIAL CONTRA PELIGROS Y PERSECUCIÓN PENAL}

Primero se va a examinar más de cerca la relación entre el derecho policial y el Derecho de procedimiento penal. El derecho policial es el derecho de la defensa policial contra peligros (Pieroth, Schlink \& Kniesel, 2004, § 2 número marginal 1 ss.). Por ende, se trata de prevenir peligros tanto presentes como futuros y prevenir con ello delitos; en consecuencia, la policía actúa preventivamente. Por el contrario, en el derecho de procedimiento penal, la persecución de delitos que han sido perpetrados en el pasado se sitúa en primer plano; los agentes de la policía actúan represivamente, como agentes de investigación de la Fiscalía (Beulke, 2006, número marginal 103).

\section{Separación fundamental y puntos comunes}

\section{Separación entre la defensa policial contra peligros y la persecución penal}

El Derecho alemán parte del principio de la separación entre la defensa policial contra peligros y la persecución penal. La defensa policial contra peligros está regulada extensamente en las leyes policiales y de orden público de cada uno de los estados federados. Por el contrario, la actuación represiva para la persecución penal se encuentra regulada como Derecho Federal en el código de procedimiento penal alemán. Por una parte, la delimitación es necesaria, porque para la intervención se requiere la debida autorización con sus correspondientes requisitos y, por otra parte, los ciudadanos, en caso necesario, deben seguir otra vía judicial contra la medida - para medidas del Derecho policial, la vía judicial contencioso-administrativa, para medidas procesal-penales, la vía judicial ordinaria (Kissel, 1999, número marginal 1y ss.; Pieroth et al., 2004, § 2 número marginal 1 ss. $§ 2$ número marginal 14 ).

que se realicen infringiendo esta prohibición no pueden se tampoco utilizadas cuando el acusado acepte su utilización". 


\section{Puntos comunes}

Sin embargo, lo que en un principio quizás podría parecer una distinción evidente entre el derecho de la defensa policial contra peligros y el derecho de la persecución penal conlleva considerables dificultades de delimitación en la aplicación práctica. En el caso presentado se observa que hay tanto componentes preventivos como represivos; de esta manera, el autor del delito debía mostrar, a través de la amenaza de tortura, el escondrijo del niño para que la vida de éste pudiera ser salvada. Por lo tanto, la actuación policial sirvió para la defensa policial contra peligros y, al mismo tiempo, se abrió un proceso penal contra el autor del delito a causa de una sospecha inicial; estaba claro que su declaración sobre el escondrijo del niño también iba a tener relevancia en el procedimiento penal, porque a través de ésta se pudo probar y confirmar la sospecha. En este sentido, la actuación de los agentes policiales sirvió a la persecución penal. La policía actuó, al mismo tiempo, preventiva y represivamente.

Por ejemplo, otros puntos comunes se pueden dar en los llamados delitos de duración, como lo es un allanamiento de morada. Si se llama a la policía por una intrusión en un piso, las medidas policiales sirven para la defensa contra el perjuicio de la paz del hogar; pero, al mismo tiempo, para la persecución penal de ese hecho. Lo mismo tiene validez cuando un delito cometido presenta el riesgo de repetirse, entonces la actuación policial puede servir, por una parte, para impedir que dicho delito se repita y, por otra, para perseguir el delito ya cometido.

Además, queda indicar que las medidas preventivas y las represivas se desdibujan cada vez más en el Derecho alemán debido a la influencia de la Unión Europea. De esta manera, en el ámbito del procesamiento de datos los sistemas electrónicos de información europeos almacenan datos unitariamente con fines tanto preventivos como represivos.

\section{Soluciones}

A continuación, se van a tratar los diversos planteamientos resolutivos para tales casos.

\section{Regulaciones legales}

En pocas ocasiones en la ley se regulan los casos de coincidencia de forma explícita. De esta forma, y según el parágrafo 81 b del código de procedimiento penal alemán ${ }^{6}$, en el marco de una investigación también se pueden tomar fotografías y huellas dactilares del acusado con fines de servicio de reconocimiento. Además, según el parágrafo 100d, párrafo 6 del código de procedimiento penal, bajo determinadas circunstancias se pueden utilizar informaciones relativas a personas provenientes de una observación acústica de un hogar por causas de la persecución penal también para la defensa policial contra peligros. Viceversa, informaciones relativas a personas que hayan sido conseguidas a través de la correspondiente medida policial, pueden ser utilizadas para la aclaración de determinados hechos delictivos graves.

\section{Decisión según el objetivo principal de la medida}

El objetivo principal de la medida policial es decisivo para el derecho aplicable (Tribunal Federal de lo Contencioso Administrativo, s.f., p. 265; Tribunal Superior Contencioso Administrativo, 1986, pp. 655 y ss.; Gusy, 2003; Schenke, 2003). Si la policía actúa de manera predominantemente preventiva, se aplica el Derecho policial y si actúa de forma predominantemente represiva, se aplica

$6 \quad$ Cuando sea necesaria la realización del procedimiento penal o si fines de servicio de reconocimiento se pueden tomar fotografías y huellas dactilares, mediciones y medidas similares del acusado también contra su voluntad. 
el Derecho de procedimiento penal (Pieroth et al., 2004, § 2 número marginal 7 y ss.; Ruder \& Schmitt, 2005, número marginal 722; Würtenberger \& Heckmann, 2005, número marginal 178). Por lo tanto, el criterio decisivo es el objetivo que persiga la policía en el momento de la actuación; sin embargo, no depende de la visión subjetiva de la policía (Würtenberger \& Heckmann, 2005, número marginal 189; Götz, 1987, p. 860), ya que si esto fuera así, quedaría en manos de la policía decidir qué autorización -quizá desde su punto de vista el más favorable- se aplicaría. Así, en la práctica podrían ser esquivadas las prescripciones procesal-penales, las cuales, con frecuencia, son las más estrictas.

Ahora bien, es más decisivo cómo se presenta una medida policial para un espectador objetivo (Würtenberger \& Heckmann, 2005, número marginal 189). Aquí debe ser tener en cuenta, sobre todo, si el deber prioritario de la policía recae en la defensa policial contra peligros o en la persecución penal. Cuando se trata de proteger bienes jurídicos de alto rango, como son el cuerpo y la vida, y cuando por esto la persecución penal es sólo un objetivo secundario, el objetivo principal recae en el momento de la medida en el ámbito de la defensa policial contra peligros (Würtenberger \& Heckmann, 2005, número marginal 191). Parcialmente, la doctrina jurídico-policial indica de forma complementaria que en caso de duda el objetivo principal recae en la defensa policial contra peligros, porque ésta supone una tarea más importante que la persecución penal (Tribunal Federal Constitucional, s.f., t. 39, p. 44; Pieroth, 2004, número marginal 15).

\section{Análisis separado de varios actos individuales}

Si una operación policial consta de varios actos individuales, la solución puede ser que una de las medidas pertenezca al ámbito de las funciones preventivas y la otra al ámbito de las represivas, por ejemplo, en el caso de que la policía pare a un conductor bebido, si éste continúa el viaje y la policía le impide por la fuerza que lo prosiga, esta acción puede estar destinada a objetivos preventivos, dado que deben ser impedidos los peligros para los demás participantes en el tráfico rodado. Si la policía le ordena consentir que se le tome una muestra de sangre, esto se hará normalmente con fines de persecución penal, ya que en caso de conducción en estado de embriaguez puede ser aplicable la norma penal del parágrafo 316 del código de procedimiento penal alemán. Igualmente, se debe decidir cuando para la defensa policial contra peligros se dispare contra un secuestrador y, tras la prevención del peligro, el secuestrador sea detenido para la persecución penal y se averigüe su identidad. La admisibilidad del tiro se juzga de acuerdo con el Derecho policial, mientras que las demás medidas tendrán naturaleza procesal-penal.

\section{Fines preventivos y represivos equivalentes}

Si excepcionalmente se persiguen fines preventivos y represivos equivalentes, la medida puede ser protegida correctamente por autorizaciones del Derecho policial y del código de procedimiento penal alemán (Würtenberger \& Heckmann, 2005, número marginal 724). Consecuentemente, para ello les debe quedar abierta a los ciudadanos tanto la vía judicial contencioso-administrativa como la vía judicial ordinaria, aunque en ese caso deban ser comprobadas todas las autorizaciones correspondientes (Schenke, 2003, número marginal, 424).

\section{Resultado provisional}

En nuestro caso inicial la policía perseguía tanto fines preventivos como represivos. No obstante, en el momento de la amenaza de tortura la salvación de la vida ocupaba claramente el primer lugar. Hasta hallar al niño secuestrado, las medidas procesal-penales podían ser aplazadas. Por lo tanto, se trataba de una medida jurídico-policial 
aunque el autor del delito era también el acusado de un sumario de Derecho penal. En este caso se habla de una "tortura preventiva".

\section{UTILIZACIÓN EN EL PROCEDIMIENTO PENAL}

La respuesta a la pregunta qué métodos para interrogar son admisibles en un sumario está en el parágrafo 136a del código de procedimiento penal alemán. Según el parágrafo 163a, párrafo 4, frase 2 del código de procedimiento penal alemán, esta prescripción también tiene validez en interrogatorios procesalpenales llevados a cabo por la policía.

Punto de partida: prohibición de la utilización de tortura según el parágrafo 136a del Código de Procedimiento Penal Alemán

Según el parágrafo 136a en conexión con el parágrafo 163a, párrafo 4, frase 2 del código de procedimiento penal alemán, la libertad de formación y puesta en marcha de la voluntad del acusado no puede ser mermada por medio de malos tratos, cansancio, intervención física, administración de remedios, tortura, engaño o a través de la hipnosis. Asimismo, está prohibida la amenaza con una medida ilícita. La prohibición también tiene validez cuando el acusado aprueba que le sean empleados esos métodos de interrogatorio. La utilización en el proceso penal de las declaraciones que han sido obtenidas por medio de métodos de interrogatorio prohibidos es ilícita, incluso, si el acusado los acepta. Lo anterior se refiere tanto a la amenaza como a la realización de una tortura en la forma de provocación de dolores, de un método de interrogatorio prohibido, en el sentido de esta prescripción.

\section{Aplicabilidad de la prescripción en medidas para la defensa policial contra peligros}

En el ejemplo expuesto resulta problemático y poco discutido que los métodos prohibidos para el interrogatorio se llevaran a cabo dentro del marco de la actividad policial que se hizo para servir a la defensa policial contra peligros. Esto es así, porque el parágrafo 136a del código de procedimiento penal alemán parte de un interrogatorio en el marco del proceso penal (Boujong, 1999, § 136 a, número marginal 1 y ss.; Meyer-Goßner, 2007, $\S 136$, número marginal 4). Sin embargo, no obstaculiza la aplicación de la prescripción, ya que la definición del interrogatorio debe ser interpretada ampliamente y debe abarcar todas las declaraciones que sean provocadas por los órganos estatales directa o indirectamete.

Además, los modelos de delimitación del derecho policial y del derecho procesal-penal han mostrado que en la actuación simultánea con fines preventivos y represivos la aplicación de prescripciones de ambos ámbitos no se descarta necesariamente. De ahí que la confesión obtenida por la policía, según el parágrafo 136a del Código de Procedimiento Penal Alemán, no sea utilizable, por lo que ninguna condena se puede basar en esto ${ }^{7}$. Si se tuviera otra percepción al respecto, sería necesario ponderar, por lo menos, la aplicación análoga de la prescripción.

\section{Efecto de continuación de la vulneración: extensión a otras confesiones del autor del delito}

En el caso inicial, el secuestrador repitió su confesión en el juicio oral ante el juzgado. Ahora se plantea la cuestión de si la condena se puede apoyar sobre esto. La jurisprudencia parte de la base de que la violación de la prohibición de la tortura en el primer interrogatorio continúa influyendo, y con esto, todas las confesiones posteriores del autor del delito son igualmente ineficaces, incluso, si no se fundamentan en métodos de interrogatorio ilícitos (Audiencia Provincial de Frankfurt, 2003, pp.

\footnotetext{
7 Igualmente para una aplicación en estos grupos de casos revisar Hecker (2003, p. 212).
} 
325 y ss.). Esto se basa en que el autor del delito en las demás declaraciones parte de la premisa de que repitiendo su primera confesión no se incrimina adicionalmente. En realidad, existe una primera carga, ya que la primera declaración no se puede utilizar.

Para que la siguiente declaración pueda ser utilizada de forma excepcional, se requiere por el juzgado una instrucción especial que declare que la declaración inicial no es utilizable (Beulke, 2006, número marginal 19; Weigend, 2003, p. 438). Además, la presión o fuerza ejercida originariamente no puede persistir para que sea posible la toma de libre decisión (Tribunal Federal Superior, t. 27, p. $358 ;$ t. 35, p. 335). El autor del delito puede decidir libremente si presta declaración o no. Tal instrucción especial también tuvo lugar en el juicio oral de nuestro caso inicial. De ahí que la confesión se pudiera utilizar en el proceso penal.

\section{Efecto a largo plazo de la vulneración: extensión de la prohibición de utilización a otros medios de prueba}

También resulta problemático si la prohibición de la utilización de la tortura, con miras a una eficacia a largo plazo también se refiere a otros medios de prueba que hayan sido conseguidos de forma mediata a la confesión por medio de la tortura.

\section{Doctrina de los frutos intoxicados ("fruit of the} poisonous tree")

La confesión del autor del delito no hubiera sido utilizada en Estados Unidos, debido a la máxima fruit of the poisonous tree, ya que en su código de procedimiento penal los frutos de una medida contraria al procedimiento son inutilizables (intoxicados). Tampoco pueden ser utilizados los medios de prueba basados indirectamente en la declaración, como las pistas obtenidas en el lugar del hallazgo del cadáver, los resultados de la autopsia o el arma del crimen encontrada gracias a ella. En Alemania esta doctrina es defendida parcialmente (Otto, 1970, p. 294; Roxin, 1998, § 24 número marginal 47).

Si se pudieran utilizar las pruebas obtenidas indirectamente, esto resultaría dudoso desde un punto de vista jurídico-estatal, ya que realmente podría ser malinterpretado como invitación a aplicar métodos prohibidos, mientras se obtengan medios de prueba utilizables procesalmente. También se vería perjudicada la confianza en la Justicia y en el Estado de Derecho, no menos que si no se condenara a un posible autor culpable de un delito. Para evitar un futuro comportamiento contrario al Derecho por parte de las autoridades de persecución penal debería ser evitado cualquier estímulo. Una investigación de los hechos a cualquier precio no es lícita.

\section{Recusación de una prohibición amplia de utilización de las pruebas}

La jurisprudencia y los autores rechazan mayoritariamente la aceptación de esta doctrina, aunque la jurisprudencia no deja ver una línea clara (Tribunal Supremo en Asuntos Penales, s.f., t. 32, p. 362; Audiencia Territorial de Hamburg, 1976, p. 601; Audiencia Territorial Stuttgart, 1973, p. 1941). Sólo en pocos casos excepcionales se ha reconocido un efecto a largo plazo (Tribunal Supremo en Asuntos Penales, s.f., t. 29, p. 347); para ello no resulta decisivo que el texto literal únicamente prohíba la utilización de la declaración, ya que la prescripción no afecta a una regulación expresa con respecto a otros medios de prueba. La razón de ello es que en Alemania -al contrario que en Estados Unidos- no tiene lugar ningún procedimiento penal contradictorio, sino que se realiza una investigación independiente de los hechos por el juzgado ${ }^{8}$. Tampoco sería compatible con la justicia material si el autor del delito probado de facto a la vista fuera absuelto. Una única vulneración del procedimiento no puede bloquear

$8 \quad$ Esto es apoyado en el $\S 160$ párrafo 2 del código de procedimiento penal, según el cual la Fiscalía también tiene que investigar las circunstancias favorables para el imputado. 
por sí misma el procedimiento penal completo, puesto que, en definitiva, sin una prohibición absoluta de utilización tampoco existe ningún estímulo para emplear métodos de interrogatorio prohibidos, ya que los ejecutivos respectivos pueden incurrir a través de ello en un delito. De otra manera se puede decidir si a través de la tortura además de la confesión del autor del delito se obliga a develar otros medios de prueba.

\section{Opinión de manera diferenciada}

En la doctrina se defiende parcialmente otra opinión de manera diferenciada:

- Examen hipotético (hypothetical clean path doctrine): en apoyo a los principios americanos se debe tomar en consideración la utilización de la tortura cuando los medios de prueba indirectamente también sin la declaración hubieran sido encontrados por la vía legal, lo cual precisa un examen hipotético (hypothetical clean path doctrine) (Beulke, 1991, t. 103, pp. 657 y ss.). Sin embargo, contra este criterio se argumenta que no se puede saber si también sin esta declaración se habrían encontrado otros medios de prueba, ya que entonces las investigaciones hubieran discurrido, naturalmente, de manera distinta.

- Ponderación entre la vulneración del proceso y la gravedad del delito: la opinión mayoritaria de la doctrina -que a su vez yo considero convincente- quiere determinar la inutilización a través de la ponderación entre el peso de la vulneración del proceso original y la gravedad del delito perseguido (Hanack, 1999, § 136a número marginal 66; Rogall, 1997, p. 948; Schlüchter, 1984, pp. 517 y ss.). En el caso presentado hay, por una parte, una grave vulneración del proceso que afecta a la dignidad humana $y$, por otra, un hecho delictivo grave -concretamente un asesinato. Sin embargo, en la ponderación se debe tener en cuenta que se amenazó con la tortura, pero no se llegó a llevar a cabo en la práctica. Además, precisamente la situación excepcional de la defensa policial contra peligros ha de ser tenida en cuenta; según ésta no sólo debe ser probada la culpabilidad del delincuente, sino que también la medida, al mismo tiempo, fue tomada para salvar la vida del niño. Al contrario que en los casos en los que los métodos de interrogatorio prohibidos sólo son empleados para la consecución de una confesión a fines de la persecución penal, la particularidad decisiva es que en este caso la policía también actuaba para la defensa policial contra peligros. Otros medios de prueba que en relación con la declaración fueron encontrados son utilizables, según esta doctrina.

\section{Conclusiones}

De lo ya dicho se deriva que también un impedimento procesal absoluto que puede desviar del principio del Estado de Derecho no entra en consideración, por lo menos, en nuestro caso inicial. Sólo en casos de maltratos o tortura más graves se puede decidir de otra manera. No quiero profundizar aquí sobre estas cuestiones constitucionales.

\section{Prohibición absoluta de la utilización de pruebas o impedimento procesal con motivo del artículo 3 del Convenio Europeo para la Protección de los Derechos Humanos y de las Libertades Fundamentales}

Al final de mi ponencia queda por responder la cuestión sobre si especialmente con motivo de pretextos internacionales, especialmente con motivo del artículo 3 del Convenio Europeo para la Protección de los Derechos Humanos y de las Libertades Fundamentales no se debería obtener un resultado distinto. El Tribunal Europeo de Derechos Humanos aún debe decidir sobre esta cuestión en nuestro caso inicial ${ }^{9}$.

$9 \quad$ El Tribunal Europeo de Derechos Humanos (2007, pp. 2461y ss.) consideró la petición como admisible. 


\section{El concepto de tortura}

El artículo 3 del Convenio Europeo para la Protección de los Derechos Humanos y de las Libertades Fundamentales prohíbe la tortura, así como la pena y el tratamiento inhumano o humillante. La prescripción no contempla excepciones; ésta es firme, según el artículo 15 del Convenio Europeo para la Protección de los Derechos Humanos y de las Libertades Fundamentales, contra estados de emergencia esto es, también en caso de guerra o de otros estados de emergencia públicos, la prescripción no puede ser limitada. Una determinación precisa del concepto de tortura se encuentra en el artículo 1, párrafo 1 de la Convención de las Naciones Unidas contra la tortura y otros tratos o penas crueles, inhumanos o degradantes, que también puede ser consultada para la interpretación de artículo 3 del Convenio Europeo para la Protección de los Derechos Humanos y de las Libertades Fundamentales. Por lo tanto, la "tortura" es todo acto con el que se inflija intencionadamente a una persona dolores o sufrimientos graves, ya sean físicos o mentales, a fin de obtener de ella o de un tercero información o una confesión, de castigarla por un acto que ella o un tercero haya cometido, o se sospeche que ella o un tercero ha cometido, o de intimidar o coaccionar a esa persona o a otras, por cualquier razón basada en cualquier tipo de discriminación, cuando dichos dolores o sufrimientos sean infligidos por un funcionario público u otra persona en el ejercicio de funciones públicas, a instigación suya, o con su consentimiento o aquiescencia.

Aplicabilidad de la prescripción en la tortura para la defensa policial contra peligros (tortura preventiva)

Con respecto a la aplicación del artículo 3 del Convenio Europeo para la Protección de los Derechos Humanos y de las Libertades Fundamentales podría resultar problemático también si un comportamiento que no debe servir primariamente a la convicción del autor del delito con fines de la persecución penal, sino primariamente a la defensa policial contra peligros, es recogido en la prohibición de la tortura. Visto desde perspectiva histórica, la tortura estaba dirigida a la confesión y tenía como finalidad obtener una condena del autor del delito (Marx, 2004, p. 278). Sabiamente, también se prohíbe la tortura preventiva, en el artículo 3 del Convenio Europeo para la Protección de los Derechos Humanos y de las Libertades Fundamentales; de igual manera, en el artículo 104, párrafo 1, frase 2 de la Ley Fundamental alemana. En éstas no sólo se limita a la persecución penal, sino que también en pocas ocasiones se pueden delimitar precisamente la actuación preventiva de la represiva. Junto a la realización de la tortura se prohíbe, con base en el fin de protección, la amenaza anterior con tortura. Esto es así, dado que puede ser considerada al menos como trato inhumano en el sentido del artículo 3 del Convenio Europeo para la Protección de los Derechos Humanos y de las Libertades Fundamentales.

Limitación de la prohibición de tortura en caso de medidas contra delincuentes

En parte se defiende por la doctrina que el ámbito de aplicación del artículo 3 del Convenio Europeo para la Protección de los Derechos Humanos y de las Libertades Fundamentales debe ser restringido bajo determinadas condiciones, si se trata de agresiones de terceros, como en el caso que se expuso (secuestro) (Grabenwarter, 2005, § 20 número marginal 21). Según esta opinión, la prescripción debe ser vista en primera línea como una reacción contra sistemas políticos totalitarios y autoritarios, que tradicionalmente se han servido de la tortura como instrumento. Por el contrario, no está prevista para los casos en que se proceda contra los delincuentes. En oposición a esta opinión se argumenta que relativizar la prohibición de la tortura conduce finalmente a su eliminación (Brugger \& Der Staat, 1996, p. 67; Jerouschek \& Kölbel, 2003, pp. 613 y ss.; Hilgendorf, 2004, pp. 
331 ss.). Verdaderamente existe una vulneración contra el artículo 3 del Convenio Europeo para la Protección de los Derechos Humanos y de las Libertades Fundamentales.

\section{Consecuencias de la vulneración}

Si en el interrogatorio se contravino el contenido del artículo 3 del Convenio Europeo para la Protección de los Derechos Humanos y de las Libertades Fundamentales, cabe preguntar si por ello se debe excluir la condena del autor del delito. En mi opinión, la vulneración del artículo 3 del Convenio Europeo para la Protección de los Derechos Humanos y de las Libertades Fundamentales en el proceso penal alemán ya ha sido compensado suficientemente con la prohibición de la utilización de la confesión como prueba. Si existen más medios de prueba que documentan la culpa del autor del delito, entonces se considerará la condena. No es mandativo otro resultado a causa de la jurisprudencia del Tribunal Europeo de Derechos Humanos, ya que las sentencias del Tribunal Europeo de Derechos Humanos no tienen efectos casatorios (Eisele, 2005, p. 392; Frowein \& Peukert, 2006, Art. 53 número marginal 3; Grabenwarter, 2005, § 16 número marginal 3). El Tribunal Europeo de Derechos Humanos puede declarar una vulneración contra la Convención de Derechos Humanos; sin embargo, éste no fija generalmente las consecuencias jurídicas que conlleva una vulneración contra la Convención. Esta decisión se deja en manos de los derechos nacionales, por eso no se debe modificar la solución que hasta ahora se deriva del parágrafo 136a del código de procedimiento penal alemán.

\section{CONCLUSIÓN}

El derecho de la defensa policial contra peligros y el Derecho procesal penal no siempre se dejan delimitar con precisión. Si se consigue una confesión del autor del delito por medio de la tortura para la defensa policial contra peligros, según el parágrafo 136a del Código de Procedimiento Penal Alemán ésta tampoco es utilizable en el proceso penal. Sin embargo, otras confesiones del autor del delito que no se basen en métodos de interrogatorio prohibidos y otros medios de prueba que sean encontrados por motivo de la confesión pueden ser utilizados. A éstos no les obstaculiza ni el artículo 3 del Convenio Europeo para la Protección de los Derechos Humanos y de las Libertades Fundamentales ni la posible culpabilidad de los agentes interrogadores. En nuestro caso inicial, el autor del delito fue condenado justamente en todo caso, ya que la subsiguiente segunda confesión tuvo lugar libremente y con conocimiento de la prohibición de utilización con respecto a la primera declaración.

\section{BIBLIOGRAFÍA}

Audiencia Provincial de Frankfurt. (2003) Strafverteidiger, 323 y ss.

Audiencia Territorial de Hamburg. (1976) En Monatsschrift für Deutsches Recht.

Audiencia Territorial Stuttgart. (1973) Neue Zeitschrif für Verwaltungsrecht, 1941.

Beulke. (1991) Zeitschrift für die gesamte Strafrechtswissenschaft (tomo 103).

Beulke. (2006) Strafprozessrecht (9a edición).

Eisele. (2005) Juristische Arbeitsblätter, pp. 390-392.

Frowein und Peukert. (2006) EMRK-Kommenar ( $2^{a}$ edición).

Götz (1987) Neue Zeitschrif für Verwaltungsrecht, 858.

Grabenwarter (2005) Europäische Menschenrechtskonvention ( $2^{a}$ edición). 
Gusy. (2003) Polizeirecht (5a edición).

Hanack. (1999) Die Strafprozessordnung und das Gerichtsverfassungsgesetz mit Nebengesetzen, Großkommentar (25ª edición).

Hilgendorf. (2004) Juristen Zeitung, pp. 331 ss.

Jerouschek und Kölbel, Juristen Zeitung, pp. 613 y ss.

Kissel (1999) Karlsruher Kommentar (4ª edición).

Leipziger. (2007) Kommentar Rönnau (12ª edición).

Ley introductoria a la ley de ordenamiento judicial (Einführungsgesetz zum Gerichtsverfassungsgesetz).

Maunz, Dürig und Herdegen. (2005) GG, 44. Lfg. Art. 1 número marginal 45 y ss.

Otto. (1970) Goltdammer's Archiv für Strafrecht, 289-294.

Pieroth, Schlink und Kniesel. (2004) Polizei- und Ordnungsrecht ( $2^{\mathrm{a}}$ edición).

Rogall. (1997). Juristen Zeitung, pp. 944-948.

Roxin. (1998) Strafverfahrensrecht (25ª edición).

Ruder und Schmitt. (2005) Polizeirecht BadenWürttemberg (6 $6^{\mathrm{a}}$ edición).

Schenke (2003) Polizei- und Ordnungsrecht ( $2^{\text {a }}$ edición).
Schlüchter. (1984) Juristische Rundschau, pp. 517 y ss.

Schönke, Schröder, Lenckner und Perron. (2006) $27^{\mathrm{a}}$ edición).

Tribunal Constitucional Federal. (2005). Neue Juristische Wochenschrift, pp. 656 y ss.

Tribunal Europeo de Derechos Humanos. (2007) Neue Juristische Wochenschrift, pp. 2461 y ss.

Tribunal Federal Consitucional. Recopilación oficial de las decisiones del Tribunal Federal Constitucional (tomo 39).

Tribunal Federal de los Contencioso Administrativo. (Sin fecha) Recopilación oficial de las decisiones del Tribunal Federal de lo Contencioso Administrativo (tomo 47).

Tribunal Federal Supremo de Asuntos Penales. (Sin fecha) Recopilación oficial de decisiones del Tribunal Federal Supremo en asuntos penales.

Tribunal Federal Supremo. (2004) Decisión del 21 de abril de 2004. Número de acta: 2 StR 35/04.

Tribunal Superior de lo Contencioso Administrativo. (1986) Neue Zeitschrif für Verwaltungsrecht, 655 y ss.

Weigend. 2003 Strafverteidiger, 436-438.

Würtenberger und Heckmann (2005) Polizeirecht in Baden-Württemberg ( $6^{a}$ edición). 